\title{
A crise financeira internacional e seus efeitos em diferentes regimes de metas de inflação: uma análise para as economias do Brasil e Uruguai
}

\author{
Adrieli Silva Pimentel \\ Fernando Henrique Taques ${ }^{* *}$ \\ Douglas Alcantara Alencar ${ }^{* * *}$ \\ Marcelo Balloti Monteiro ${ }^{* * * *}$
}

Resumo: Diante da crise financeira instalada nas economias dos Estados Unidos e dos países europeus, a partir de 2008, coube aos países da América Latina a adoção de estratégias, em nível macroeconômico, que contivessem possíveis efeitos dessa crise em suas economias. Nesse esforço, Brasil e Uruguai lançaram mão de instrumentos de políticas monetárias, dado o entendimento particular da magnitude da crise em questão sobre suas economias. Nessa perspectiva, o objetivo central desta pesquisa é analisar quais foram as medidas adotadas por esses dois países, a saber, Brasil e Uruguai, diante da crise econômica vigente, levando em consideração o sistema de metas de inflação adotado por ambos e quais foram os desempenhos econômicos obtidos, posteriormente medidos sob as variáveis produto interno bruto, inflação, taxa de juros e taxa de câmbio. A análise comparativa indica que a incerteza desempenha um papel relevante na determinação da meta inflação estabelecida pelo país e contribui na determinação de políticas que afetam o resultado do produto da Economia.

Palavras-Chave: Crise financeira. Economia Brasileira. Economia Uruguaia.

\section{The international Finance Crises and it effects on different target inflation regimes: Analyzing the Brazilian and Uruguayan economies}

\begin{abstract}
Through the 2008 financial crisis that emerged in U.S and European countries, Latin American countries have adopted strategies on macroeconomics fields that restrained possible effects of this crisis on their economies. In this effort, Brazil and Uruguay call upon instruments of monetary and exchange policies, given the particular understanding of the magnitude of the crisis over their economic. Thus, the main goal of this research is scrutinize what kind of measures has adopted by this two countries in this financial crisis, mainly in relation to the inflation target regime, which both countries has embraced, and what was the economic performance in some economics variables regarding the GDP, inflation, interest and exchange rates. The comparative analysis indicates that uncertainty plays a major role in determining the inflation target set by the country, also contributes in setting policies which affect the result of the product of the economy.
\end{abstract}

Keywords: Financial Crises. Brazilian Economy. Uruguayan Economy.

Classificação JEL: G01, N1.

\footnotetext{
*Economista pela FMU e MBA em Business Economics pela EESP/FGV. E-mail: drispimentel@gmail.com

** Mestre em Economia pelo PEPGEP/PUC e Professor das Faculdades Metropolitanas Unidas (FMU) e do Centro Universitário SENAC/SP. E-mail: fernandohtaques@gmail.com

**** Doutorando em Economia pelo Centro de Desenvolvimento e Planejamento Regional (Cedeplar), Universidade Federal de Minas Gerais (UFMG). E-mail: dougsky@gmail.com

**** Economista pela PUC-SP e Mestre em Economia Política pela PUC-SP. Foi docente nas Faculdades Metropolitanas Unidas (FMU) por três anos. E-mail: marorestes@ hotmail.com
} 


\section{Introdução}

A problemática inflacionária é algo estudado por todas as principais correntes de pensamento econômico. Entre o período do final da Segunda Guerra Mundial e o primeiro choque do petróleo (1971), conhecido como período de Grande Moderação, o tema fícou, de certo modo, esquecido dado o relativo controle dos níveis de preços.

A década de 1970 marcou o retorno de um cenário com elevação de preços, em termos generalizados, por todo o mundo desenvolvido, e reativou as preocupações desses países em entender o processo inflacionário e como combatê-lo. Pesquisas passaram a questionar as proposições monetaristas com relação à inflação, e novos argumentos foram postos em discussão.

Os economistas conhecidos como novos clássicos, adeptos da teoria das expectativas racionais, avançaram na questão da inflação com proposições acerca do que ficou conhecido como Regime de Metas de Inflação (RMI). Esse regime foi pautado na escolha de uma meta pontual de inflação (âncora monetária), com ou sem uma banda de flutuação, cujo nível de preços poderia flutuar. Todavia, para a execução desse modelo, os Bancos Centrais deveriam ser independentes do regime político como forma de lograrem êxito em sua execução.

As posições divergentes sobre a inflação estão diretamente ligadas ao papel da moeda na Economia e à percepção de como afeta as decisões dos agentes. Sem uma percepção clara das distintas funções e atribuições da moeda no sistema econômico, não é possível estabelecer os limites e as políticas para tentar dirimir os problemas monetários da Economia.

A questão da neutralidade da moeda no longo prazo, proposição que é base da teoria novo-clássica, e a não neutralidade da moeda que está no cerne do arcabouço keynesiano, é um ponto conflitante entre duas das principais escolas do pensamento econômico, e o debate monetário sobre esta relação é de suma importância para a compreensão e a efetividade do Regime de Metas de Inflação.

Independentemente da posição teórica em relação ao tema, o RMI foi implantado no Brasil em 1999, após a crise cambial que o País sofreu a partir das crises cambiais dos países em desenvolvimento na década de 1990. Não obstante, a Economia do Uruguai seguiu caminho similar após a crise financeira de 2002, adotando, mesmo que no primeiro momento de forma não explícita, um regime baseado no controle de agregados monetários, de forma a reduzir os efeitos da inflação. 
Após a adoção do controle sobre as taxas de juros, tanto Brasil quanto Uruguai se viram diante de um novo cenário dado pela crise financeira internacional, originária da Economia americana em 2007. Considerando a magnitude da Economia americana, os efeitos da crise geraram não apenas reflexos na Economia desse país, mas também sobre o continente europeu e demais países, inclusive os países da América Latina.

Nesse sentido, o objetivo deste trabalho é estudar o desempenho das economias do Brasil e do Uruguai em um período pré-crise econômica internacional, uma vez que já haviam sido adotados controles dos níveis de preços, além da conduta mediante tal crise que distribui efeitos sobre as economias do mundo.

Assim, a pesquisa está estruturada em três seções, além da introdução e da conclusão. A primeira levanta o debate teórico sobre metas de inflação sob a perspectiva de algumas escolas de pensamento. Já a segunda parte aborda os desempenhos das economias do Brasil e do Uruguai anteriormente à crise internacional de 2008, enquanto a última parte contempla uma análise comparativa das economias desses dois países após a eclosão da crise americana.

\section{Metas de inflação}

A estabilidade dos preços e sua manutenção a longo prazo são as principais preocupações dos bancos centrais, pois assim criam condições favoráveis para o crescimento da Economia. A justificativa dessa preocupação tem como base o elevado custo social de um processo inflacionário crônico, caracterizado por aumento da incerteza sobre as condições futuras e sobre os resultados das atividades empresariais, o estímulo ao imposto inflacionário, as distorções na estrutura de impostos e na alocação de recursos com incentivo às aplicações financeiras em detrimento dos investimentos em atividades produtivas (OREIRO,2008, p. 8).

\subsection{A perspectiva novo-clássica}

Na abordagem novo-clássica, o Banco Central utiliza instrumentos da política monetária para o alcance da meta estabelecida, dando, assim, uma previsibilidade à Economia de modo a evitar o problema da falta de transparência, que gera um consequente aumento de incertezas sobre o futuro e a possibilidade de comportamento discricionário das autoridades monetárias, que prejudica a formulação de expectativas por parte dos agentes (OREIRO, 2008, p. 200).

Os pressupostos básicos, inerentes à adoção do sistema de metas de inflação, são: 
a) o único objetivo da Política Monetária é a convergência da inflação à meta (STUDART et al., 2000);

b) $\mathrm{O}$ reconhecimento da neutralidade da moeda no longo prazo (DEBELLE, et al., 1995);

c) Aceitação da Curva de Phillips no longo prazo, proposta por Friedman e Phelps, a qual afirma que não há trade-off entre inflação e nível de atividade (DERZODI, 2004).

Os autores dessa abordagem fundamentam os pressupostos em quatro pilares principais: a) equilíbrio contínuo de mercado, com salários e preços reais flexíveis; b) neutralidade da moeda; c) hipótese de expectativas racionais; e d) existência de viés inflacionário na política econômica que gera inconsistência temporal (FREITAS, 2009, p. 14).

Os agentes racionais não estão sujeitos à ilusão monetária. Confundem-se, pois sabem o que sugere a Teoria Quantitativa da Moeda (TQM), em que maior oferta monetária provoca inflação. De acordo com Friedman (1959, p. 16) apud Modonesi (2005, p. 87), “[...] no longo prazo, a renda real e a velocidade [de circulação da moeda] tendem a se mover em direções opostas; com relação aos ciclos de curto prazo, na mesma direção".

Sendo assim, essa linha de pensamento não apoia a atuação do Governo, pois não devem utilizar a política monetária de forma discricionária, mas sim, utilizar políticas baseadas em regras claras e preestabelecidas, evitando um ambiente de incertezas em relação ao comportamento do Governo. Sugerem, portanto, que o Banco Central tenha atuação independente para executar a política monetária (FREITAS, 2008, p. 8).

Mishkin (2001) propõe que o regime de metas de inflação apresenta cinco elementos básicos: a) o anúncio público de uma meta numérica para inflação no médio prazo; b) um compromisso institucional com a estabilidade do preço como objetivo primordial da política monetária, sendo os demais objetivos subordinados; c) informações, inclusive estratégicas, sobre várias variáveis e não apenas sobre agregados monetários e a taxa de câmbio, que são empregadas para determinar a utilização dos instrumentos de política; d) maior transparência na estratégia da política monetária, por meio da comunicação com o público e o mercado, esclarecendo planos, objetivos e decisões das autoridades monetárias; e) ampliação da "responsabilidade" do Banco Central no atingimento da meta de inflação estabelecida.

Para que a autoridade monetária consiga influenciar as expectativas de inflação, sua atuação deve ser por meio de políticas críveis. O controle da meta é tido, basicamente, pela manipulação da taxa básica de juros, isso com o intuito de fazer com que tanto a inflação efetiva 
quanto as expectativas de inflação convirjam novamente para a meta (OREIRO, PAULA; SOBREIRA, 2009, p. 74).

Esse regime de metas inflacionárias tem sido visto no mundo como uma fuga aos problemas que envolvem a condução da política monetária, problema principal, como a insistência de bancos centrais de tentar apropriar-se do trade-off entre inflação e desemprego. Nesse caso, a teoria convencional já estabelece que tais tentativas não são viáveis para legar o nível de equilíbrio de produto e emprego a longo prazo (OREIRO et al., 2009, p. 98).

Portanto, a política monetária no regime de metas de inflação é discricionária sob o argumento de que a manipulação da política monetária é livre desde que seja comprometida com a convergência da inflação para a sua meta, ou seja, “[...] a discrição é permitida para responder sensivelmente a choques não antecipados" (ARESTIS; SAWYER, 2003, p. 6). Verifica-se, então, que difere das regras dos outros regimes monetários clássicos, contribuindo para a manutenção da credibilidade das autoridades monetárias.

\subsection{A perspectiva Keynesiana}

A Economia monetária Keynesiana (isso inclui o próprio Keynes e os chamados novos keynesianos) apresenta forte oposição ao que é visto na Economia clássica (incluindo a chamada escola novo-clássica). Uma das discordâncias centrais entre estas escolas do pensamento econômico é exatamente o papel da moeda na Economia.

Keynes atribui grande relevância a esse assunto, ainda antes de escrever sua obra magna. Em $O$ tratado sobre a moeda, o autor busca examinar o que ficaria conhecido como uma Economia monetária, ou seja, um sistema produtivo onde a moeda teria relevância na alteração das variáveis reais, seja a curto ou a longo prazo. Portanto, o autor questiona dois aspectos centrais da Economia clássica: a neutralidade da moeda e a dicotomia clássica (CARVALHO, 1988, p. 16-17).

Ao atribuir importância, antes negligenciada por economistas do mainstream, à moeda, os economistas pós-keynesianos atestam que a moeda é endógena ao sistema econômico. Por endogeneidade da moeda entende-se que a liquidez do sistema econômico é função direta dos atos dos bancos e das instituições financeiras que compõem a Economia e que estão diretamente relacionados ao financiamento das atividades produtivas (LIBÂNIO, 2004, p.8).

Por conseguinte, a moeda é função das necessidades de crédito, que são inerentes à atividade econômica, sendo que essa possui relação direta com a demanda agregada. Logo, “[...] 
variações no estoque monetário são geradas 'dentro' do sistema, fazem parte do sistema normal da Economia, e são efeito (não causa) das flutuações do produto e dos preçoo" (LIBÂNIO, 2004, p.9).

Então, pela perspectiva de que a moeda é gerada dentro do próprio sistema econômico, a política monetária também ganha outra conotação. Nesse contexto, mais relevante que as atuações diretas na oferta monetária, por meio da manipulação da taxa de juros de curto prazo, os chamados mecanismos indiretos de atuação da autoridade monetária ganham relevância substancial. Ao exercer influência no estado de expectativas dos agentes, o equilíbrio no mercado de crédito (oferta e demanda por moeda) pode ser modificado via alteração no comportamento tanto dos agentes privados como dos agentes do sistema financeiro (LIBÂNIO, 2004, p.9).

Nesse sentido, o rumo da política monetária em geral e da política monetária em Keynes e pós-keynesianos não é imutável, considerando que as expectativas dos agentes não se comportam dessa forma como observa Carvalho (1994, p. 53). "O mero reconhecimento da incerteza é suficiente para que se conclua pela impossibilidade de traçar a priori regras de validade geral para a conduta das autoridades tanto quanto para qualquer agente privado" (OREIRO; PAULA; SOBREIRA, 2009, p. 100).

Minsky (1975), em seu estudo, mostra que a instabilidade inerente às economias capitalistas possui dimensões financeiras, representada por investidores e banqueiros. Reforça, assim, que a política de regras não é capaz de sustentar o emprego, podendo até levar à exacerbação de crises, se as autoridades monetárias insistirem na obediência à regra (OREIRO; PAULA; SOBREIRA, 2009, p. 102).

Nesse tipo de Economia, vislumbrada por Keynes, é possível atribuir à moeda uma dupla função, a saber: unidade de conta e meio de pagamento. Isso se traduz na transformação da moeda em um ativo, uma riqueza que permite ao seu possuidor transportar, ao longo do tempo, sua posse sem perdas de valor. A aceitação da moeda como riqueza traz um papel diferente à política monetária, pois ela é capaz de alterar a quantidade de ativos líquidos à disposição, mesmo levando em consideração as diferenças que existem em matéria de grau de liquidez dos diversos ativos da Economia, e, assim, os preços dos outros ativos tendem a variar (OREIRO; PAULA; SOBREIRA, 2009, p. 56-57).

Logo, segundo Oreiro, Paula e Sobreira (2009), a abordagem de Keynes com relação à política monetária não possui influência apenas na Economia, no aspecto da oferta dos meios 
de pagamento, mas, também, gera um efeito sobre a disponibilidade de ativos líquidos ante outras classes de ativos.

Sendo assim, a moeda tem um papel central na formação do pensamento dos economistas ligados a Keynes, como os novos keynesianos. Conforme Ferrari Filho (1996, p.71), no mundo pós-keynesiano, a moeda tem sua relevância tanto a curto como a longo prazo, o futuro é incerto (refutação da ergodicidade clássica), todos os contratos são denominados em termos monetários e o desemprego é resultado do lado monetário da Economia.

\subsection{A Economia novo-keynesiana}

A Economia novo-keynesiana surge como uma crítica à Economia novo-clássica. Esse último arcabouço teórico enfraqueceu-se, dado que um de seus pressupostos é de que havia apenas o desemprego voluntário e friccional, o que não se comprovou empiricamente (LOPEZ; ALENCAR, 2012; AMORIM, 2002)

Explicar a rigidez de preços e salários, assim como as imperfeições do mercado, é o principal objetivo dessta escola do pensamento econômico, principalmente quando a Economia é analisada a curto prazo. Para tanto, partem de fundamentos microeconômicos, contudo negando a microeconomia walrasiana (SICSÚ, 1999, p.85-86; LOPEZ; ALENCAR, 2012; AMORIM, 2002).

Os dois principais fundamentos microeconômicos, que são utilizados como explicação para tal rigidez, são os chamados "custos de menu" e "salário eficiência". O primeiro está intimamente ligado a possíveis desequilíbrios no mercado de bens, enquanto o último relacionase ao mercado de trabalho.

Na visão de Sicsú (1999, p.86-87), o custo de menu é o gasto que uma empresa poderá incorrer quando se tem o desejo de alterar o preço dos seus produtos. Em realidade, é um gasto mais alto que o que se incorre para etiquetar o seu produto e para a divulgação dos novos preços aos consumidores.

Ainda com relação aos custos de menu, Mankiw (1990) afirma que eles:

[...] can explain in rigorous microeconomic terms the failure of price setters to restore equilibrium. Monopolistically competitive firms do not have much incentive to cut their prices when the demand for their goods declines. Yet because of the preexisting distortion of monopoly pricing, the bene- fit to the society of a price cut may be large (first-order) even when the benefit to the firm is small (second-order). If firms face even a small menu cost, they might maintain their old prices, despite the substantial social loss from this price stickiness (MANKIW, 1990, p.1657). 
A teoria de salário eficiência é um grande contraponto à teoria de mercado de trabalho, vivenciada na Economia clássica. Sicsú (1999, p.89) aponta que, ao estabelecer esse tipo de remuneração na Economia, existiria uma barreira impeditiva de queda no salário real que permitisse a eliminação do excesso de um possível excesso de oferta de trabalhadores. Em tese, as empresas, mesmo em situação de aumento no número de desempregados, não diminuiriam os salários monetários dos seus empregados em temor a uma provável redução da produtividade dos mesmos.

Essa relação entre queda na produtividade dos trabalhadores e os salários monetários é destacada por Mankiw (1990, p. 1658) no que tange à lealdade dos empregados: a) salários reais mais baixos desestimulam os empregados e, possivelmente, os tornam menos leais às corporações; b) problemas de seleção adversa: salários monetários mais baixos devem provocar a perda dos trabalhadores mais capacitados; c) risco moral: dado que monitorar os trabalhadores é algo custoso e difícil, quando o salário real é reduzido, o empregado sente-se estimulado a ser mais leniente no cumprimento de suas obrigações trabalhistas.

A partir da explanação dos componentes teóricos que compõem o arcabouço teórico novo-keynesiano, há elementos suficientes para analisar a questão da política monetária para estes economistas, bem como o regime de metas de inflação, regime monetário utilizado em diversos países mundo afora.

A condução da política monetária, convencionou-se, por Clarida, Gali e Gertler (1999), como sendo novo-keynesiana:

[...] because in their model nominal price rigidities allow monetary policy to have non-neutral effects on real variables in the short run, there is a positive short-run relationship between output and inflation (that is, a Phillips curve), and the ex ante real interest rate is negatively related to output (that is, an IS function) (SNOWDON; VANE, 2005, p. 415).

Para a melhor eficiência do regime de metas de inflação, alguns autores apontam que deve haver flexibilidade com relação à meta central de aumento do nível de preços, visto que existem incertezas com relação ao futuro (SNOWDON; VANE, 2005, p. 415). É digno de nota que a incerteza está entre um dos elementos-chave que compõem a fundamentação teórica dos economistas novo-keynesianos. 


\section{Inflação no Brasil e Uruguai: uma análise pré-crise}

\subsection{Adoção do Sistema de Metas de Inflação no Brasil}

A crise cambial do Brasil no ano de 1999 foi um marco que trouxe mudanças na dinâmica de atuação da política cambial e monetária. Tal fato fomentou a discussão da adoção do regime de câmbio flutuante e do regime de metas inflacionárias. As perdas de reservas fizeram com que o Governo adotasse a flutuação cambial, e, assim, o câmbio passou a ser determinado pelo mercado, passando a flutuar de acordo com a oferta e demanda de divisas. Como resultado, houve uma rápida e significativa desvalorização de aproximadamente $66 \%$ do câmbio no período (MISSIO, 2008, p. 22).

Embora tenha ocorrido a estabilização em termos de nível de preços, a valorização cambial adotada nos anos anteriores gerou não apenas efeitos negativos no nível de reservas, mas também elevação no déficit público e no balanço de pagamentos, além de contribuir para uma baixa taxa de crescimento. Assim, a crise evidenciou a sobrevalorização da moeda brasileira, o que refletiu em uma alteração na política cambial via adoção do câmbio flutuante, mas também na condução da política monetária por meio do sistema de metas de inflação (IAHN; MISSIO, 2009). Em junho de 1999, o País adotou o sistema de metas de inflação (inflationtargeting) para que a política monetária voltasse a ser referenciada (THÁ, 2008, p. $67)$.

Diante desse cenário, o principal objetivo era fazer com que as expectativas negativas em relação à estabilidade do nível de preços fossem amenizadas. A implantação veio acompanhada de um choque de credibilidade, pois atestava-se, perante a lei, a responsabilidade do Banco Central quanto aos níveis de preços. O Conselho Monetário Nacional (CMN) era a instância responsável pela indexação da meta que reúne o Ministério da Fazenda e o Planejamento, além do Presidente do Banco Central (OLIVEIRA, 2005, p. 202). Em 30 de junho de 1999, o CMN escolheu o índice de Preços ao Consumidor Amplo (IPCA) para ser o balizador oficial do sistema de metas. Tal escolha respeitava a restrição feita pelo decreto-lei em que se exigia a escolha de um índice amplamente conhecido ${ }^{1}$ (THÁ, 2008, pg. 67).

\footnotetext{
${ }^{1}$ Nesse contexto o CMN também decidiu por estabelecer bandas de dois pontos percentuais para mais ou para menos do centro da meta e caberia ao Banco Central como responsável pelo seu cumprimento, endereçar uma carta formal ao Ministério da Fazenda caso o não cumprimento da meta estabelecida (THÁ, 2008, pg. 67). No regime de metas de inflação, é também responsabilidade do Banco Central em publicar trimestralmente um relatório sobre a inflação, abordando as perspectivas em relação à mesma de modo a estreitar o vinculo de transparência e comunicação com a sociedade e o mercado (BOGDANSKI, TOMBINI e WERLANG, 2000, p. $10)$.
} 
Na Figura 1, o principal instrumento utilizado para a transmissão da política monetária no sistema de metas é a taxa de juros, pois sua influência sobre o nível de preços se dá por meio da influência dos juros na demanda. O esquema de mecanismo de transmissão da política monetária é dado por:

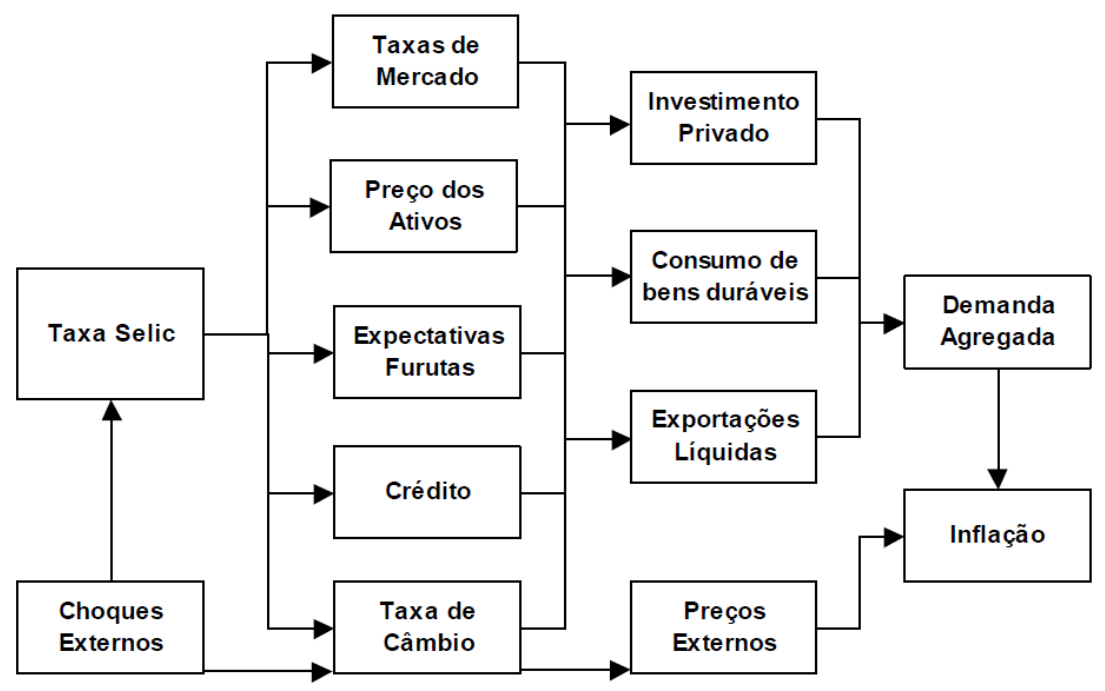

Figura 1: Esquema de mecanismo de transmissão da política monetária Fonte: MISSIO (2008).

O Comitê de Política Monetária (COPOM) possui a função de definir as diretrizes da política monetária e a taxa básica de juros do Sistema Especial de Liquidação e Custódia (SELIC) do País, com objetivo de manter a inflação sob controle por meio das mudanças da taxa básica de juros.

\subsection{Desempenho da economia brasileira pré-crise internacional sob o sistema de metas de inflação}

A análise do desempenho do regime de metas de inflação no Brasil passa pelo entendimento de outras relações econômicas envolvidas, quanto ao entendimento do desempenho econômico do país.

O ano de 2000 apresentou indícios de recuperação da Economia, visto que o cenário apresentava estabilidade do câmbio ao longo do ano e a ausência dos choques externos, sejam eles advindos de outros países emergentes ou do aumento dos preços das commodities importadas, como o petróleo e o trigo (MISSIO, 2008, p. 26). No final desse mesmo ano, houve resultados positivos no controle da inflação, visto que nos anos de 1999 e 2000 o objetivo foi atingido, a inflação ficou dentro da meta estabelecida. 
Todavia, o que se viu, na análise dos anos subsequentes, mais precisamente nos três anos seguintes, foi uma sequência de fracassos na busca de estabilização de preços, colocando em cheque a política monetária adotada no País (MEOTTI, 2009, p. 53). A crise da Argentina afetou diretamente a Economia brasileira, visto que esse país era membro do Mercado Comum do Sul (MERCOSUL), que viabilizava o livre comércio a países membros sem tarifas comerciais. A Argentina, nessa época, era o principal país exportador para o Brasil. Entretanto, no mês de junho, o Conselho Monetário Nacional abandonou a meta estabelecida para aquele ano, passando a seguir a meta estipulada para o ano de 2003, que foi elevada para 4,0\% (passando a ter um intervalo de tolerância de 2,5 pontos percentuais) (MEOTTI, 2009, p. 56). O Banco Central, em janeiro de 2003, propôs, em carta aberta ao então Ministro da Fazenda, uma elevação da meta para o IPCA, fixando em 8,5\%. O Governo se comprometia com a reafirmação da condução da política monetária, além da manutenção da responsabilidade fiscal. Para firmar tal compromisso, o Governo aplicou na Economia um choque de credibilidade (MISSIO, 2008, p. 35). Já em 2004, o IPCA atingiu o nível de 7,6\%, valor abaixo do limite superior de $8,00 \%$, Os preços livres registraram variação de $6,55 \%$, em 2004 , contra 7,79\%, em 2003, ao mesmo tempo em que a variação dos preços monitorados reduziu-se para $10,19 \%$ em 2004 e para 13,2\% no ano anterior (MEOTTI, 2009, p. 59).

Segundo o relatório de inflação divulgado pelo BACEN, em março de 2005, esse resultado refletiu a recuperação da demanda interna, decorrente da evolução favorável dos fundamentos econômicos, o que estimulou investimentos, e das melhores condições de crédito e ampliação gradual da renda, além do crescimento da demanda externa (MEOTTI, 2009, p. $62)$.

Passando a discutir a questão da taxa de câmbio, a cotação da PTAX800², em 1999, iniciou o ano em $\mathrm{R} \$ 1,80$ por US\$1,00, com uma tendência de queda até o mês de março, quando fechou o mês em $\mathrm{R} \$ 1,75$. Perante tal situação, foi iniciado um movimento moderado de alta, fechando o ano em R \$ 1,96 por US\$1,00 (MEOTTI, 2009, p. 52).

Tal resultado, de leve estabilização, ocorreu em detrimento de um cenário de confiança do País, o que trouxe, como consequência, a entrada de dólares e a atuação do Banco Central na compra de moedas para recompor reservas a fim de evitar a depreciação do real.

Importante notar que a taxa de câmbio, até o final de 2002, sofreu desvalorização, contudo. A partir de 2003, após processo eleitoral e com o aumento dos preços internacionais

\footnotetext{
2 Conforme dicionário de finanças do Bovespa, Ptax= Taxa média ponderada dos negócios realizados no mercado interbancário de câmbio com liquidação em dois dias úteis, calculada pelo Banco Central do Brasil
} 
das commodities, a taxa de câmbio sofreu uma grande valorização saindo de algo próximo a 3,5 em 2003, e atingindo o valor próximo de 2,00 R\$/US\$ em 2006.

Em relação à taxa de juros, a situação em 2000 abriu espaço para uma flexibilização na política monetária, pois a taxa SELIC teve um comportamento descendente durante todo o ano, fechando com $15,8 \%$ (a.a.). O IPCA acumulou alta de quase $6 \%$, pouco abaixo do centro da meta definida para o período (MEOTTI, 2009, p. 52).

Assim, o COPOM manteve, em 2002, a meta da taxa SELIC em 18\%, com inflação acima de $6 \%$ em 2002, entretanto, com inflação projetada para o ano seguinte abaixo de 4,0\%. Todavia, a expectativa do COPOM, em relação à trajetória da inflação, mais uma vez, não se concretizou (MEOTTI, 2009, p. 57).

Dado o processo de aceleração da inflação, foi estabelecido, no final do ano de 2002 e começo do ano de 2003, o aumento das taxas de juros. No entanto, a partir de maio de 2003, atingiu um ápice de 16,0\%. A partir de então, entrou-se em uma trajetória descendente, finalizando o ano em $9,0 \%$, o que justifica a queda de juros antes do mês de junho, quando se iniciou efetivamente o processo de redução de juros da política monetária (MEOTTI, 2009, p. 59).

Em seguida, o BACEN deu início a uma política de redução na taxa básica de juros até o mês de agosto de 2004, quando atingiu-se a cotação mínima do ano de 15,8\%. Diante da atuação dos índices de preços, que começaram a apresentar sinais de elevação, a autoridade monetária começou um ciclo de elevação da taxa básica, o que apresentou, como resultado, uma elevação na taxa SELIC, que fechou o ano na cotação máxima de 17,2 \%. A SELIC, em 2005, manteve-se acima de 19\% praticamente durante todo o ano. Em janeiro, atingiu 17,7\%, e, no final do primeiro semestre, já estava em torno de 19,8\%. A decisão foi tomada considerando o resultado do IPCA, que acumulava alta de 3,1\% em maio (MEOTTI, 2009, p. $59-60)$.

\subsection{Produto Interno Bruto, nível de atividade e balança comercial}

Além dos fatores citados, a recuperação da Economia, entre 1999 e 2000, deu-se, também, pela retomada do controle da situação monetária. Fato esse que fez com que os empresários conseguissem se planejar e investir em suas empresas e, ainda, com que os consumidores refizessem seus planos de consumo, principalmente de bens duráveis (THÁ, 
2004, p. 82). Com isso, a retomada de confiança dos agentes econômicos fez impulsionar a taxa de crescimento do PIB, ficando em torno de, aproximadamente, 4,3\% (THÁ, 2004, p. 82).

Em 2001, a crise de energia elétrica se deu pela grande dependência de usinas hidrelétricas, aliada à falta de chuva nos anos precedentes, resultando na queda dos reservatórios das empresas, e forçando, assim, o Governo a decretar racionamento de energia (THÁ, 2004, p. 85). Esse fato trouxe grande impacto sobre a indústria nacional e abalou negativamente o crescimento do PIB.

Já em 2002, puxado principalmente pela agropecuária, o PIB variou positivamente em 2,7\%. Mesmo com o crescimento maior do que o apresentado no ano de 2001 (1,3\%), o produto interno manteve-se aquém do seu hiato (THÁ, 2004, p. 90). No ano de 2002, o desempenho ainda discreto do PIB recaía única e exclusivamente sobre a aplicação da política monetária restritiva durante todo o primeiro semestre, o que comprometeu o crescimento do ano inteiro.

Em 2003, mesmo com o nível de inflação atingindo patamares de 9,3\% ao ano, o resultado do produto foi discreto. O ótimo desempenho da balança comercial, que trouxe capitais líquidos de US\$24,82 bilhões, foi responsável pela relativa melhoria do produto. $\mathrm{O}$ PIB da indústria variou negativamente em $0,96 \%$ e o setor agroindustrial cresceu 4,99\% (THÁ, 2004, p. 95).

No mesmo período, China atingiu crescimento da Economia de 9,1\%, a Argentina 8,4\%, a Rússia 7,3\%, a Malásia 5,2\%, os EUA 3,1\% e o México 1,3\%. O desempenho foi ainda pior ou tão ruim quanto o das principais economias da região do Euro, terrivelmente atingidas pela valorização de sua moeda ocorrida ao longo do ano, da ordem de $19,7 \%$, e seus efeitos no comércio internacional da região (THÁ, 2004, p. 95).

O saldo da balança comercial atingiu US $\$ 44,8$ bilhões, com as exportações atingindo US\$ 118,3 bilhões e crescimento de 22,6\% sobre o ano anterior. As importações chegaram a US\$ 73,5 bilhões e crescimento de 17,1\% sobre o ano de 2004. O superávit em transações correntes foi de US\$14,2 bilhões, representado por 1,79\% do PIB. (MEOTTI, 2009, p. 60). 
Tabela 1: Saldo da Balança Comercial Brasileira

\begin{tabular}{c|r|r|r|r}
\hline \multirow{2}{*}{ Balança Comercial } & \multicolumn{2}{|c|}{2004} & \multicolumn{2}{c}{2005} \\
\cline { 2 - 5 } & \multicolumn{1}{|c|}{ Dezembro } & \multicolumn{1}{c|}{ Jan- Dez } & \multicolumn{1}{c}{ Dezembro } & \multicolumn{1}{c}{ Jan- Dez } \\
\hline Exportação & 9.919 .239 & 97.204 .775 & 10.911 .399 & 121.203 .306 \\
\hline Importação & 5.684 .160 & 62.815 .073 & 6.550 .690 & 73.536 .228 \\
\hline Saldo & 4.235 .079 & 34.389 .702 & 4.360 .709 & 47.667 .078 \\
\hline
\end{tabular}

Nota: Valores expressos em US\$1.000 FOB

Fonte: Receita Federal

Cabe, ainda, mencionar que a balança comercial brasileira continuou a financiar o déficit brasileiro nas transações com o restante do mundo, conta esta que engloba todos os envios de dinheiro de juros, dividendos, royalties, entre outros, para o exterior. Com isso, o ano de 2005 foi considerado um ano de superações e de crescimento, visto que o Real se manteve no ritmo de valorização com taxa de câmbio de R \$US\$ 2,62 no início do ano, encerrando o período em R\$/US\$ 2,34 (MEOTTI, 2009, p. 60). O aumento do PIB foi resultado da elevação de 2,1\% do Valor Adicionado a preços básicos e do aumento de 3,9\% nos impostos sobre produtos, enquanto o PIB per capita apresentou crescimento de $0,8 \%$ no mesmo ano.

\subsection{Diretrizes para inflação no Uruguai}

Segundo Cuitiño, Tramontín e Vicente (2011), na Economia Uruguai, cabe ao Banco Central o controle da inflação, cuja conduta é pautada sob a forma progressiva de metas de inflação. Para tanto, o índice de preços ao consumidor (IPC) serve como base para medidas relativas à política monetária.

De maneira análoga ao Brasil, que enfrentou a crise cambial no final da década de 1990, o Uruguai passou, a partir de dezembro de 2001, também por uma profunda crise financeira.

Entre 1999 e 2002, o país apresentou uma trajetória declinante do PIB. Essa tendência foi mais acentuada em 2001, devido a uma crise bancária, em parte agravada pelo colapso da Economia da Argentina, mas, também, originária por fraquezas dentro do próprio setor financeiro uruguaio. Nesse cenário, coube ao Governo intervir na Economia de modo a assegurar a estabilidade do sistema, isso por meio da intervenção nos bancos com o objetivo de evitar o efeito contágio para o sistema como um todo (PLAZA; CIRTAINE, 2005).

Cancela (2008, p. 195) argumenta que a crise uruguaia consistiu na fuga de metade dos depósitos do sistema bancário do país em um período de apenas sete meses, montante esse 
equivalente a cerca de $30 \%$ do PIB na época, acompanhado de abrupta queda no nível de reservas.

Tal desempenho foi marcado por uma série de fatores, internos e externos, tais como: a) queda na atividade da Economia devido à perda de competitividade com o Brasil, associada à crise cambial do país em 1999; b) alta na taxa de juros internacional e no preço do petróleo; c) queda acentuada dos preços de bens exportados pelo país, como carne, lã e arroz; d) período de seca que impactou diretamente os setores agropecuários e, como efeito, refletindo em queda nas exportações do país, assim como na geração de energia; e) indícios de febre aftosa que prejudicaram ainda mais as exportações de carne (BUCHELI; FURTADO, 2005, p. 170).

A reversão dessa trajetória, segundo Zunino (2010), esteve relacionada com uma mudança na conduta da política monetária, ou seja, por meio de medidas que contaram com a redução da vulnerabilidade da Economia e da inflação, mudanças essas adotadas pelo Governo do país e não meramente por ações de mercado. Pontualmente, segundo o autor, a Economia do país estava, na época, menos vulnerável a choques externos em comparação a décadas anteriores.

Os resultados da crise implicaram um aumento de grande ordem sobre o nível de pobreza em decorrência de políticas fiscais restritivas. Como resultado, o Governo adotou uma nova conduta na política cambial, em 2002, ao abandonar o câmbio administrado com flutuação suja para o câmbio flutuante. Tal medida buscou, como objetivo central, a redução da inflação, naquele instante em um nível em torno de $20 \%$, e também para conter o pass-through (repasse da desvalorização cambial nos níveis de preços). Tais condutas surtiram efeitos em pouco tempo na Economia do país. As medidas permitiram reduzir em grande medida a dolarização da Economia, acompanhada de uma redução na dívida do Uruguai. Tais fatores contribuíram para obtenção do superávit, primeiro no ano de 2003, e redução do patamar da inflação (CANCELA, 2008).

Garda, Lanzilotta e Mantero (2006), de maneira complementar, apontam que, a partir de 2002, a política monetária passou a ser gerenciada a partir de controles dos agregados monetários $(\mathrm{M} 1)^{3}$, tendo como objetivo o controle da inflação. Adicionalmente, caberia ao Banco Central do Uruguai a intervenção no mercado de câmbio visando tal cumprimento.

\footnotetext{
${ }^{3} \mathrm{O}$ M1 é composto pela moeda em poder do público e depósitos à vista de bancos comerciais.
} 


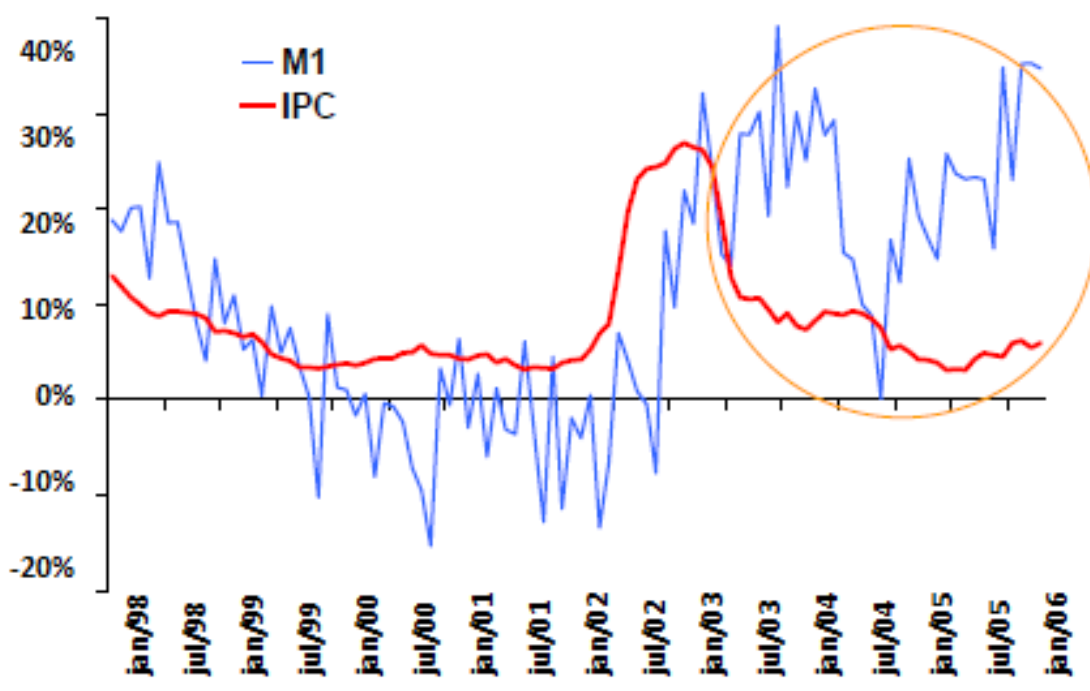

Gráfico 1: Inflação e M1 do Uruguai (taxas de variação 12 meses) (1998-2006) Fonte: Garda, Lanzilotta e Mantero (2006)

Segundo os autores, o M1 cresceu a partir de 2002 em um ritmo maior do que a inflação. Bucacos e Licandros (2003) explicam que a premissa que parte de uma relação não razoavelmente estável entre M1 e nível de preços. Para a manutenção de tal estratégia, houve uma política que buscava o equilíbrio fiscal. Como resultado, a Economia logrou crescimento nos anos seguintes.

Diante dessa conduta na política monetária, os resultados foram efetivos. Por um lado, o ápice da inflação ocorreu em março de 2003, com a taxa de 28,51\% e, a partir da nova conduta monetária, obteve-se uma redução para apenas um dígito, já no ano de 2004. A partir de então, a inflação, segundo dados do Banco Central do Uruguai, converge para um valor entre $4 \%$ e 9\%, até o ano de 2007. Tais valores estiveram dentro da meta estabelecida pelo Comitê de Política Monetária do Banco Central do Uruguai (BCU), definida para a banda entre 7\% e 9\%.

A mudança no perfil da política monetária também pode ser evidenciada pela taxa de juros real do Uruguai. Ao final da década de 1990, a taxa real constava em uma trajetória constante em torno do nível de $40 \%$. Entretanto, com a crise financeira, houve um crescimento para acima de $90 \%$ no ano de 2002, diante de um cenário de crise financeira instaurada no sistema financeiro do país. Com a nova regra da política monetária, a taxa de juros real declinou acentuadamente para, aproximadamente, $10 \%$ em 2004, e manteve sua trajetória de queda até 2006. Assim, como resultado, houve a inflexão da trajetória de crescimento econômico a partir de 2004, distintamente da variação negativa do PIB de anos anteriores. O Uruguai apresentou taxas crescentes do PIB superior ao nível de 4\%, a partir desse período até o ano de 2007. 


\section{Efeitos da crise sobre as economias do Brasil e Uruguai}

Após a eclosão da crise americana em 2008, diversas economias sofreram os impactos, mas, sob diferentes magnitudes. Alguns países sofreram de maneira mais acentuada, principalmente no continente europeu, refletindo diretamente sobre sua atividade econômica enquanto outros conduziram tal adversidade com resultados menos negativos.

Brasil e Uruguai, no tocante à taxa de câmbio, apresentaram trajetórias distintas a partir da eclosão da crise financeira. Primeiramente, cabe mencionar que a taxa de câmbio no Brasil possui uma paridade centrada em torno de dois Reais para cada Dólar Americano, enquanto no Uruguai essa relação gira em torno de 20 Pesos por Dólar (em 2012) ${ }^{4}$.

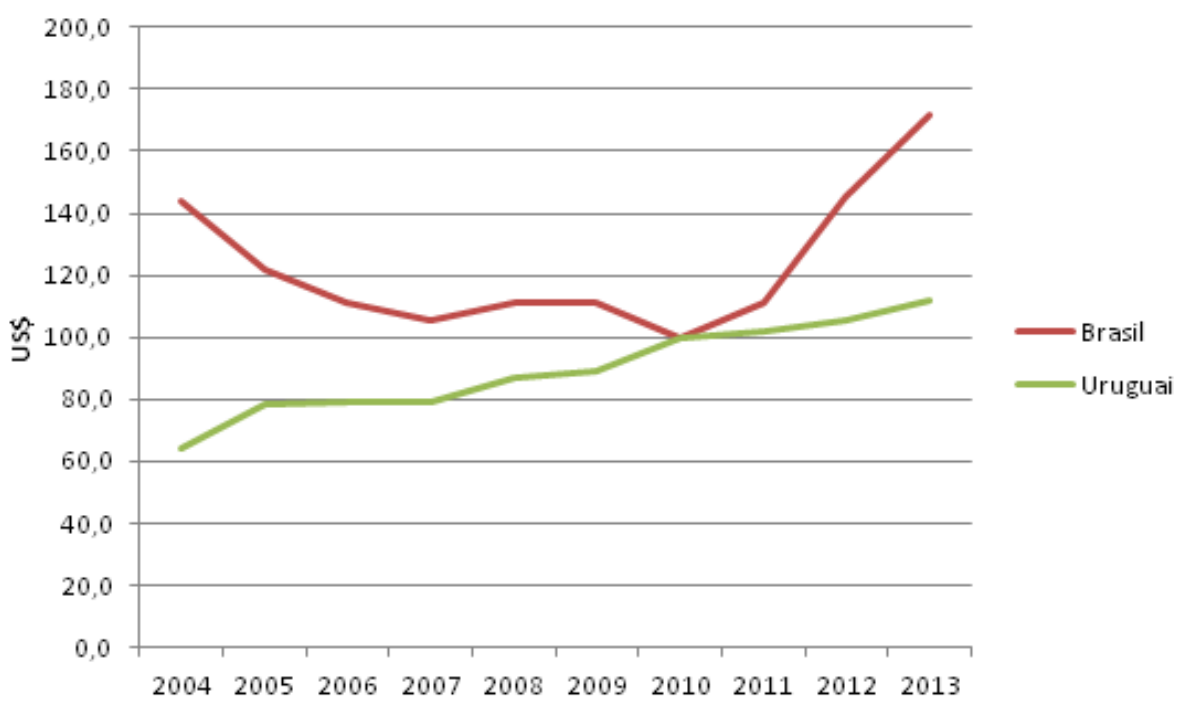

Gráfico 2: Taxa de Câmbio Real e Efetiva Brasil e Uruguai (2004-2013) ${ }^{5}$ Fonte: Banco Mundial e IPEADATA.

Nota: Contas Nacionais ano-base 2000 = Ano base (100) e metodologia de contas nacionais de 1993

A Economia do Uruguai apresentou tendência de desvalorização cambial desde 2004, enquanto, no Brasil, houve uma apreciação cambial até 2010, movimento esse que foi revertido a partir de 2010, quando a taxa de câmbio real e efetiva passou a se desvalorizar.

\footnotetext{
${ }^{4}$ Cabe mencionar que a taxa de câmbio no Brasil não é estável ao longo do período, mas apresenta uma magnitude de variação inferior à da economia uruguaia no período em questão.

5 Para o Uruguai, a taxa de câmbio real e efetiva foi coletada junto ao Banco Mundial (Indicadores de desenvolvimento mundial). Essa variável é a taxa de câmbio nominal, mensurada em valores da moeda local, levando em consideração o peso médio de várias moedas estrangeiras, dividido pelo deflator de preços. Para o Brasil, a taxa de câmbio real e efetiva foi coletada junto ao IPEADATA, medida da competitividade das exportações brasileiras calculada pela média ponderada do índice de paridade do poder de compra dos 16 maiores parceiros comerciais do Brasil. A paridade do poder de compra é definida pelo quociente entre a taxa de câmbio nominal (em R \$/unidade de moeda estrangeira) e a relação entre o Índice de Preço por Atacado (IPA) do país em caso e o Índice Nacional de Preços ao Consumidor (INPC/IBGE) do Brasil. As ponderações utilizadas são as participações de cada parceiro no total das exportações brasileiras em 2001.
} 
Garayalde (2013) observa que a Economia uruguaia, nesse período, foi caracterizada pelo uso tanto da moeda nacional (Peso) quanto estrangeira (Dólar), essa última recorrente para transações imobiliárias, compra de veículos e eletrodomésticos, entre outros. Desse modo, é possível afirmar que a Economia do país é altamente dolarizada, medida esta que buscou ser revertida pelo Governo do país por meio da troca do perfil da dívida nacional, incentivando compras em Pesos e títulos públicos. Além disso, houve incentivo para os residentes no país utilizaram a moeda nacional em detrimento do Dólar.

Por sua vez, a taxa de juros também indica trajetória diferente entre os países a partir da crise econômica americana de 2008. Enquanto no Brasil a taxa declinou no ano em questão, no Uruguai há indícios de um leve aumento no ano de 2009, com uma posterior queda nos anos seguintes. É possível observar, também, que a taxa de juros no Brasil é muito superior à exercida no Uruguai.

Esse movimento sinaliza que o Brasil buscou promover um impulso da atividade econômica no período da crise por meio da redução da taxa de juros, ao passo que o Uruguai sinalizou uma preocupação maior com uma Economia vulnerável, ainda em detrimento da crise monetária de poucos anos antes. Inicialmente, a medida buscou incentivar o ingresso de recursos em moeda estrangeira no país para conter efeitos advindos da crise americana no

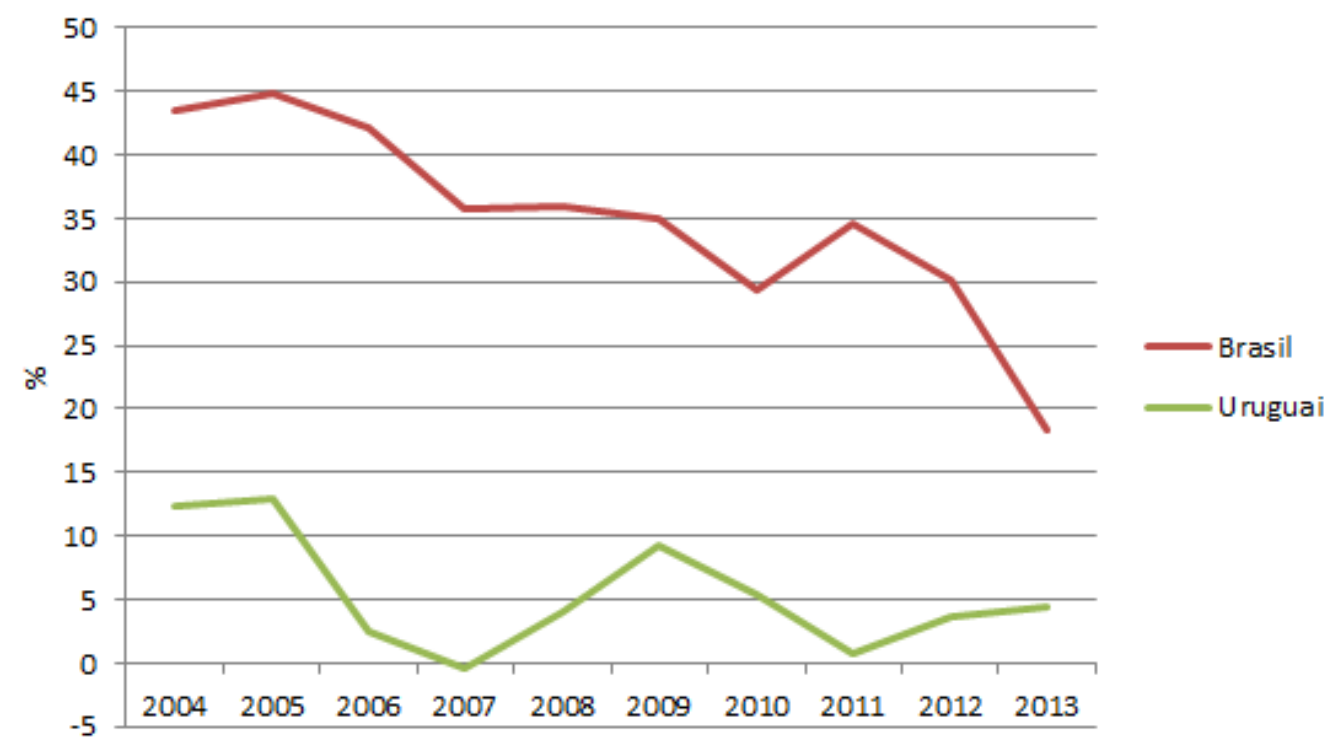

Uruguai.

Gráfico 3: Taxa de Juros Real Brasil e Uruguai (2004-2013) ${ }^{6}$

Fonte: Banco Mundial (Indicadores de Desenvolvimento Mundial).

Nota: Contas Nacionais ano-base 2000 = Ano base (100) e metodologia de contas nacionais de 1993

\footnotetext{
${ }^{6}$ Taxa real de juros é a taxa de juros de empréstimos ajustados para a inflação medida pelo deflator do PIB. Os termos e condições a que os juros do crédito diferente entre os países, o que, sabemos, limita a comparação. A nosso ver, mesmo com esse problema, foi a forma encontrada para analisar os países comparativamente.
} 
Para o produto, por outro lado, os países indicaram trajetória similar com relação ao crescimento econômico, sugerindo um possível efeito da crise americana sobre as economias em análise. A partir de 2008, as economias do Brasil e Uruguai tiveram uma acentuada queda na taxa de crescimento, cuja recuperação somente foi observada em 2010. Contudo, a Economia do Uruguai apresentou taxas de crescimento acima das brasileiras durante todos os anos (período entre 2006 e 2012).

Uma possível explicação para esse crescimento uruguaio, acima do verificado no Brasil, esse fato pode ter sido motivado pela tendência de desvalorização cambial, que pode ter influenciado as exportações do país, permitindo que muitas pessoas desempregadas voltassem ao mercado de trabalho, também ampliando a demanda agregada da Economia via consumo. Já o Brasil aproveitou-se principalmente o bom momento, vivido pelos elevados preços das commodities agrícolas e minerais no mercado internacional, e, principalmente, pós eclosão da crise financeira, pela fartura de crédito e isenções fiscais que estimularam o consumo doméstico, além da queda na taxa de juros.

Por fim, a análise centra-se nos dados para a inflação. Primeiramente, é importante considerar que a meta de inflação vigente no Uruguai é uma banda entre $4 \%$ e $6 \%$, com sinalização para o período de 2014 entre 3\% e 7\%. Já no Brasil, a meta para 2013 estabelecida é de $2,5 \%$ a 6,5\%, com previsão de manutenção para o ano seguinte.

Isso posto, é possível observar que o Brasil tem obtido resultado satisfatório quanto à meta imposta para a inflação no período entre 2006 e 2012, distintamente do Uruguai. Nesse caso, a mudança de conduta do Banco Central do Uruguai é exatamente no sentido de flexibilizar o nível de inflação, buscando centralizar-se dentro da meta da inflação.

A partir de 2007, quando o Governo uruguaio anunciou o valor pretendido da taxa de câmbio, percebe-se que isso contribuiu para uma redução da inflação acumulada. Ademais, os efeitos recessivos da crise financeira contribuíram para que a Economia do país permanecesse, em dois anos (2009 e 2010), dentro da meta estabelecida.

Assim, diante dos argumentos postos pelos estudiosos da Economia novo-clássica e póskeynesiana, é possível observar que a primeira atribui à política monetária um papel livre dentro do regime de metas de inflação, respondendo a choques não antecipados. Já a segunda é regida por uma flexibilidade dentro da meta estabelecida, visto que há incertezas advindas da complexidade do ambiente econômico.

Sob esse referencial, é possível notar que tanto o Brasil quanto o Uruguai foram suscetíveis a mudanças estabelecidas para o centro da meta de inflação. A incerteza advinda 
dos efeitos trazidos pela crise americana, gerada em 2008, refletiu em posturas diferentes dos países, isso em medidas pautadas na condução que a Economia já vinha adotando, e na perspectiva que os efeitos da crise poderiam trazer para suas economias. Como consequência, tal incerteza sobre os efeitos da crise gerou alteração na expectativa do nível de inflação, refletindo no estabelecimento de novas metas, assim como medidas relativas à taxa de câmbio, taxa de juros e outras políticas que se refletem, diretamente, sobre o nível de produto do país.

\section{Considerações finais}

O objetivo da pesquisa consiste em compreender as medidas tomadas pelos governos do Brasil e do Uruguai frente à crise econômica deflagrada no ano de 2008, e quais foram os desempenhos econômicos apresentados pelos países no período imediatamente subsequente.

Para compreender tal dinâmica, são listados os principais conceitos sobre o regime de inflação e o papel da moeda na Economia, sob a perspectiva da escola novo-clássica e póskeysianos. Enquanto os primeiros defendem a livre movimentação para o equilíbrio, os póskeynesianos argumentam que a incerteza é um importante atributo nessa definição.

Os resultados para os primeiros anos da adoção do novo modo de condução da política monetária, em ambos os países, foram satisfatórios, no que tange ao controle dos níveis de preços e na comunicação da autoridade monetária, que é de suma importância na ancoragem das expectativas dos agentes econômicos.

Obviamente, nenhuma proposta de política econômica está imune a críticas, e um dos principais questionamentos, acerca do RMI no Brasil, é a persistência da taxa de juros de curto prazo (SELIC) estar em patamares sempre elevados para o controle dos níveis de preços, o que tende a causar uma retração nos níveis de investimentos da Economia e, por conseguinte, em crescimentos módicos no Produto Interno Bruto (PIB) do País. Contudo, é salutar que essa tendência tenha sido revertida nos anos que antecedem a crise americana de 2008, e ela não modificou, em grande medida, esse efeito de queda nos últimos anos.

Já no Uruguai, a taxa de juros, situada abaixo do nível da Economia brasileira, também apresenta tendência de queda no início dos anos 2000, mas a crise de 2008 pode ter contribuído para o aumento da taxa de juros diante desse novo cenário.

Além disto, as bandas de flutuações do RMI em ambos os países (2,5\% a 6,5\% no Brasil e 3\% a 7\% no Uruguai) são alvos de questionamentos, uma vez que, quanto maiores as bandas, menor pode ser o compromisso do gestor da política monetária em conduzir a inflação para o 
centro da meta e, portanto, menor pode ser a credibilidade do regime, fazendo com que a ancoragem das expectativas aplique em uma deterioração. Essa flexibilidade das bandas busca, justamente, o ajuste da meta em casos de incerteza, tal como versa a perspectiva póskeynesiana.

\section{Referências}

ARAÚJO, Assilio Luiz Zanella de. Avaliação crítica do regime de metas de inflação a partir de uma ótica pós-keynesiana. 2007. 26 pg. Dissertação (Mestrado em Economia) Faculdade de Ciências Econômicas da URFGS, Porto Alegre, 2007.

AMORIM, Ricardo Luiz Chagas. Macroeconomia neoclássica contemporânea: novoskeynesianos e novos-clássicos. Ensaios FEE, vol. 23, n 1, 2002.

BACHA, Edmar Lisboa. O Plano Real: uma avaliação. In: MERCADANTE, Aloisio (org). O Brasil pós real: A política econômica em debate. Campinas, SP: Unicamp. Instituo de Economia, 1998.

BAER, Werner. A Economia brasileira. São Paulo: Nobel, 1996.

BANCO CENTRAL DO BRASIL Disponível em <http://www.bcb.gov.br/?CARTAMETA>. Acesso em 25.08.2013

BANCO CENTRAL DO BRASIL. Regime de metas para a inflação no Brasil. Série Perguntas mais Frequentes, 2013. Disponível em < http://www4.bcb.gov.br/pec/gci/port/focus/FAQ\%2010-

Regime\%20de\%20Metas\%20para\%20a\%20Infla\%C3\%A7\%C3\%A3o\%20no\%20Brasil.pdf>. Acesso em 12 de setembro de 2013.

BANCO CENTRAL DO BRASIL. Relatório de inflação, 2005. Disponível em <http://www.bcb.gov.br/?RELINF>. Acesso em 22.04.2013

BANCO CENTRAL DEL URUGUAY. Disponível em <http:// www.bcu.gub.uy>. Acesso em 25.08.2013

BANDA, Ariel. El banco central en la economía uruguaya. Revista de Economía - Banco Central Del Uruguay, Segunda Epoca, v. 1. n. 15, Maio, 2008.

BATISTA JUNIOR, Paulo Nogueira de. O plano real à luz da experiência mexicana e argentina. Estudos Avançados, v. 10, n. 28, setembro/dezembro, 1996. crossref http://dx.doi.org/10.1590/S0103-40141996000300007

BERNANKE, Ben S.; LABAUCH, Thomas; MISHKIN, Frederic S.; POSEN, Adam, S. Inflation targeting: Lessons from the international experience. Princeton: Princeton University, 1999.

BRESSER-PEREIRA, Luiz Carlos; NAKANO, Yoshiaki. Uma estratégia de desenvolvimento com estabilidade. Revista de Economia Política, v. 22, n. 3, p. 146-180, jul.-set/2002. 
BOGDANSKI, Joel; TOMBINI, Alexandre, Antonio; WERLANG, Sérgio Riberio C. Implementing inflation targeting in Brazil. Brasília: Banco Central do Brasil, Working Paper Series, n.1, Julho/2000.

BUCACOS, Elizabeth; LICANDRO, Gerardo. La demanda de dinero en Uruguay: 1980.12002.4. Revista de Economía - Banco Central Del Uruguay, Segunda Epoca, Vl. X, nº 2, Novembro, 2003.

BUCHELI, Marisa; FURTADO, Magdalena. Uruguay 1998-2002: La distribución del ingreso en lãs crisis. Revista de La Cepal, n. 86, agosto/2005.

CANCELA, Walter. Política monetária en el Uruguay: Manejo y perspectivas. Papers and Proceedings - Política Monetaria en El Uruguay, p. 195-199, 2008.

CARDOSO, Ricardo Lopes; MENDONÇA, Octavio Ribeiro; OYADOMARI, José Carlos; ANJOS, Ana Claudia. A ilusão monetária e a informação contábil e financeira. Revista Universo Contábil, vl. 6, n. 2, 2010.

CARVALHO, Fernando J. Cardim; SOUZA, Francisco E. P.; SICSÚ, João; PAULA, Luiz Fernando Rodrigues de; STUDART, Rogério. Economia Monetária e Financeira: Teoria e política. São Paulo: Ed. Campus, p.214-233, 2000.

CARVALHO, Fernando Cardim de. Da síntese neoclássica à redescoberta de Keynes. Revista Análise Econômica, ano 6, n. 9, novembro/87 a março/88.

CLARIDA, Richard; GALI, Jordi; GERTLER, Mark. The science of monetary policy: a new keynesian perspective. National Bureau of Economic Research, 1999.

CUITIÑO, Fernanda; TRAMONTIN, Fiorella; VICENTE, Leonardo. Evaluación de indicadores de inflación subyacente para Uruguay. Banco Central Del Uruguay. Documento de Trabajo, n. 011, 2011.

DAVIDSON, Paul. The neoclassical vs. post keynesian view of government. Controversies in post keynesian economics. Aldershot, UK: Edward Elgar, 1991.

DEPARTAMENTO INTERSINDICAL DE ESTATÍSTICA E ESTUDOS

SOCIOECONÔMICOS. A inflação e os juros. São Paulo, 2013. Disponível em $<$ http://www.dieese.org.br/sitio/buscaDirigida?tipoBusca=eixo\&valorBusca=POL\%CDTICA S+P\%DABLICAS> Acesso em 19.04.2013.

FARHI, Maryse. Análise comparativa do Regime de Metas de Inflação. Instituto de Economia - Universidade de Campinas - UNICAMP, Texto para discussão n. 127, julho/2007.

FERRARI FILHO, Fernando. Da tríade mobilidade de capital, flexibilidade cambial e metas de inflação à proposição de uma agenda econômica alternativa: Uma estratégia de desenvolvimento para a Economia à luz da teoria pós-keynesina. Universidade Federal do Rio Grande do Sul, Textos para discussão, n. 14, novembro/2002.

"Keynesians", monetarists, new classical and new keynesians. Faculdade de Ciências Econômicas - UFRGS, Análise Econômica, ano 14, março/96 a setembro/96.

FREITAS, Maria Cristina. Regime de metas de inflação em perspectiva comparada. In: BIASOTO JUNIOR, Geraldo; NOVAIS, Luis Fernando; FREITAS, Maria Cristina. 
Panorama das economias internacional e brasileira: Dinâmica e impactos da crise global. São Paulo: Fundap, p. 98-122, 2009.

FRIEDMAN, Milton. The demand for Money: Some theoretical and empirical results. The Journal of Political Economy, v. 67, n.4, p. 327-351, 1959. crossref http://dx.doi.org/10.1086/258194

GARAYALDE, Elena Ganón. Tipo de cambio, intervenciones y política monetaria em Uruguay en el corto plazo. Anais do XXVIII Jornadas Anuales de Economía, Banco Central del Uruguay, Montevideo, 2013.

GARDA, Paula; LANZILOTTA, Bidiana; MANTERO, Rafael. Agregados monetários e inflación en Uruguay: ¿Una relación no lineal? Centro de Investigaciones Económicas CINVE, 2006.

HILLBRECHT, Ronald. Metas de inflação e política fiscal. Revista Brasileira de Economia, vl.55, n.3, Rio de Janeiro, Julho/Setembro, 2001.

IAHN, Jaicy Fidelis; MISSIO, Fabrício Jose. Uma revisão da macroeconomia brasileira dos anos 90: O mix da política fiscal, monetária e cambial. Pesquisa \& Debate, SP, v. 20, número 1 (35), pp. 1-29, 2009.

INSTITUTO BRASILEIRO DE GEOGRAFIA E ESTATÍSTICA. Disponível em <http://www.ibge.gov.br/home/> . Acesso em 22.03.2014.

IPEADATA. Disponível em: <http://www.ipeadata.gov.br>. Acesso em 14.02.2013

LANZANA, Antonio Evaristo Teixeira. Economia brasileira: fundamentos e atualidade. São Paulo: Ed. Atlas, 2002.

LIBÂNIO, Gilberto A. Temas de política monetária: uma perspectiva pós-keynesiana. Belo Horizonte: UFMG/Cedeplar, 2004.

LOPES, R. O; ALENCAR, D. A. Curva de Phillips: Os casos de Brasil e EUA de 1999-08. Revista de Economia (Curitiba), v. 38, p. 81-114, 2012.

LOPES, Mariana de Lourdes Moreira; MOLLO, Maria de Lourdes Rollemberg. Regime de metas de inflação, regra de Taylor e neutralidade da moeda: uma crítica pós-keynesiana.

Anais do XIV Encontro Nacional de Economia Política, São Paulo, 2009.

MALAN, Pedro S. Uma crítica ao Consenso de Washington. Revista da Economia Política, São Paulo, v.11, n.3, p. 1-8, jul/set, 1991.

MANKIW, Nicholas Gregory. A quick refresher course in macroeconomics. Journal of Economic Literature, vl. XXVIII, dezembro/1990.

MARGARIDO, Mario Antônio. A questão cambial e a balança comercial no Brasil pós-Plano Real. Informações Econômicas, SP, vol. 31, n 11, novembro/2001.

MENDONÇA, Helder Ferreira. Metas de Inflação: uma análise preliminar do caso brasileiro. Revista Economia Aplicada, vl. 5, n.1, p. 129-158, Jan/Mar 2001.

MEOTTI, Fabio Vinícius. Implantação e evolução do sistema de metas de inflação no Brasil. 2009. 89p. Dissertação (Mestrado em Desenvolvimento Econômico - Universidade Federal do Paraná, Curitiba, 2009. 
MERCADANTE, Aloisio. Plano Real e o neoliberalismo tardio. In: MERCADANTE, Aloisio (org). O Brasil pós-real: A política econômica em debate. Campinas, São Paulo: UNICAMP - Instituto de Economia, 1998.

MINSKY, Hyman. Stabilizing an unstable economy. New Haven: Yale University Press, 1986.

MISSIO, Fabrício José. Uma revisão da macroeconomia brasileira dos anos 90: O mix da política fiscal, monetária e cambial. 2008. 29p. Tese (Mestrado em Economia) - Universidade Estadual de Mato Grosso do Sul, MS, 2008.

MODONESI, André de Melo. Regimes monetários: Teoria e experiência do real. Barueti: Manole, 2005.

OREIRO, José Luis. Metas de inflação: Uma avaliação do caso brasileiro. 2005. 25p. Tese (Doutorado em Economia) - Universidade Federal do Paraná, 2005.

OREIRO, José Luis; SICSÚ, João; PAULA, Luiz Fernando Rodrigues de. Controle da dívida pública e política fiscal: uma alternativa para um crescimento autossustentado da Economia brasileira. In: SICSÚ, João; OREIRO, José Luis; PAULA, Luiz Fernando Rodrigues de (orgs). Agenda Brasil: Políticas econômicas para o crescimento com estabilidade de preços. Barueri: Manole/Fundação Konrad Adenauer, 2003.

OREIRO, José Luis; PAULA, Luiz Fernando Rodrigues de; SOBREIRA. Rogério. Política monetária, bancos centrais e metas de inflação. 1. São Paulo, Ed. Fundação Getúlio Vargas, 2009.

PADILHA, Rodrigo Ayres. Metas de inflação: experiência e questões para os países em desenvolvimento. 2007. 120p. Dissertação (Mestrado em Desenvolvimento Econômico) Universidade Federal do Paraná, Curitiba, 2007.

PIO, Carlos. A estabilização heterodoxa no Brasil: Ideias e redes políticas. Revista Brasileira de Ciências Sociais, São Paulo, v. 16, n. 46, junho/2001.

PLAZA, Luis de La; SIRTAINE, Sophie. An analysis of the 2002 uruguayan banking crisis. World Bank Policy Research Paper, n. 3780, Dezembro/2005.

POMAR, Valter. O Brasil endividado. São Paulo: Perseu Abramo, 1996.

RIGOLON, Francisco. A atuação do Banco Central em uma Economia estabilizada: é desejável adotar metas inflacionárias no Brasil? Revista de Economia Política, v. 19, n.3, julho-setembro/1999.

SICSÚ, João. Expectativas inflacionárias no regime de metas de inflação: Uma análise preliminar do caso brasileiro. Economia Aplicada, v. 6, n. 4, p. 703-711, 2003. abri/1999 a junho/1999.

Keynes e os novos-keynesianos. Revista de Economia APlicada, v. 19, n.2,

SICSÚ, João; VIDOTTO, Carlos. A. A administração fiscal no Brasil e a taxa de juros. In: SICSÚ, João (org.). Arrecadação e gastos públicos: De onde vem, para onde vão? São Paulo: Boitempo, p. 110-119, 2007.

SNOWDON, Brian; VANE, Howard. Modern Macroeconmics: its origins, development and current state. Cheltenham: Edward Elgar, 2005. 
SILVA, Fábio José Ferreira da. Expectativa de Inflação sobre o Regime de Metas de Inflação no Brasil. 2005, p75. Dissertação (Mestrado em Economia) - Escola de Economia de São Paulo da Fundação Getúlio Vargas, São Paulo, 2005.

TAVARES, Maria da Conceição. A Economia política do Real. IN: MERCADANTE, Aloisio (org). O Brasil pós-real: a política econômica em debate. Campinas, São Paulo: UNICAMP - Instituto de Economia, 1998.

THÁ, Daniel. Uma análise da performance do sistema de metas inflacionárias no Brasil. 2004. 104p. (Monografia em Ciências Econômicas) Curitiba: FAE Business School, 2004.

TOSTES, Felipe Santos. Regime de metas de inflação no Brasil: Uma análise dos efeitos transmissores da política monetária sobre a inflação e o produto. 2010. 120 p. Dissertação (Mestrado em Economia) - Faculdade de Ciências Econômicas da URFGS, Porto Alegre, 2010.

WILLIAMSON, John. Exchange rate regimes for emerging market: Reviving the intermediate option. Ed. Institute for International Economics, 2000.

WORLD BANK. World development indicators. Disponível em $<$ http://data.worldbank.org/data-catalog/world-development-indicators>. Acesso em 10 jun 2014.

ZUNINO, Gonzalo. La eficiencia de la política monetaria como instrumento estabilizador en Uruguay. Centro de Investigaciones Económicas - CINVE, 2010. 